\title{
EDITORIAL
}

\section{A Crise na Universidade}

"Que se passa com a Universidade brasileira?" Explicome: qual a razão fundamental que nos leva a ter uma Universidade em crise permanente, com falta de recursos, admitindo muitas vezes pessoas desqualificadas e rejeitando ou eliminando outras de alta capacidade? No início do regime militar, demitiram-se da Universidade de Brasília 208 professores, antes altamente selecionados. Este fato foi assistido pelo governo com indiferença, senão com regozijo. Foi uma manifestação aguda de uma situação crônica e representa o desrespeito, o pouco-caso, a falta de confiança no papel da Universidade e no que ela possa fazer nas ciências e nas artes entre nós. E, apesar dos pesares, ela tem feito muito. Temos um imenso potencial. Aqui mesmo, quando foi Vice-Reitor de Pesquisas o Prof. Heonir Rocha, a nossa Universidade deu uma contribuição insuspeitada, mostrando do que é capaz de realizar no campo de pesquisa cientí. fica, se convenientemente direcionada e estimulada como foi. Mas, a nossa crise é crônica. Por quê? Os especialistas, os tecnocratas, os cientistas sociais, todos têm se dedicado a estudos profundos sobre a Universidade, mas creio que ainda há lugar para uma apreciação de conjunto, não importa quão ingênua ela seja, feita por alguém que durante os últimos 30 anos esteve dentro dos muros da Universidade, vivendo e lutando com os seus problemas. Creio que, quando analisamos que houve falta de verbas, que a reforma foi deturpada, que os departamentos não se constituíram em unidades didático-administrativas como deveriam ser, que a hierarquia desapareceu, que os salários-reais dos professores e funcionários foram aviltados, que os equipamentos não foram renovados, que os hospitais Universitários, sem o apoio orçamentário oficial e discriminados pelo INAMPS, tiveram de funcionar precariamente ou fechar as suas portas, que se tentou a todo custo implantar o ensino pago, etc, estamos realmente apontando fatos cruciais, mas que, na minha opinião, são epifenômenos dependentes de uma causa mais geral. Esta pode ser encontrada quando adotamos uma análise com uma perspectiva histórica mais abrangente. Por aí poderemos tentar deslindar o paradoxo de uma sociedade que, ao mesmo tempo, procura desenvolver um importante parque industrial, inclusive com indústrias de "ponta" como a bélica, a aeronáutica, a da informática, da energia nuclear, da bio-tecnologia, da comunicação por satélites, coincidentemente com a decadência da sua
* Parte do discurso proferido pelo Prof. Zilton Andrade por ocasião do recebimento do titulo de Professor Emérito da Universidade Federal da Bahia. em 21.03.85
Recebido para publicação em $15 / 04 / 85$. 
Universidade, que obviamente deveria estar na base para garantir o contínuo e indispensável progresso de um programa tão ambicioso. Na realidade, esta sociedade está historicamente condicionada a produzir e exportar matériasprimas e a importar tudo o que necessita, insistindo na ilusão de que se pode importar progresso tecnológico através de "pacotes" e "caixas pretas" e que assim se vai conseguir algum dia a tão propalada transferência de tecnologia. Simplesmente, a tecnologia não se transfere através da obtenção de patentes ou da importação de produtos acabados ou semi-acabados, mas pelo desenvolvimento harmônico dos conhecimentos, pelo avanço da ciência básica, e é à Universidade que justamente está reservado este papel. Todavia, no nosso tipo de desenvolvimento dependente, não se espera que a Universidade seja inquieta, contestatória, renovadora, mas sim dócil e ordeira, para produzir os técnicos para operar as máquinas sofisticadas, mas não para inventá-las ou modificá-las; para refletir e acompanhar os avanços científicos e artísticos dos povos mais desenvolvidos, mas não necessariamente para gerar aqui novos avanços e novas contribuições. Na realidade, face à grandeza e ao potencial do nosso país e do nosso povo, vamos ter de caminhar para uma Universidade que se integre na sua comunidade e seja fator precípuo de progresso e de mudanças. Uma Universidade que tenha um orçamento à altura das suas finalidades e responsabilidades, e que este seja encarado com seriedade, prioridade e compreensão pelos governantes. Uma Universidade com plena liberdade, em que os debates e os entrechoques das idéias tenham curso, para que a luta dos contrários possa gerar o progresso. Uma Universidade que difunda o conhecimento, mas que não cesse de procurar o novo, nas ciências como nas artes. Evidentemente que esta Universidade não surgirá simplesmente do desejo, do empenho e do engenho e arte dos seus dirigentes, mas deverá ser reclamada e efetivada por uma nova sociedade, justa e livre, que aspirará ao progresso e à paz para todos os seus membros. Inversamente, somente uma sociedade dependente, desigual, atrasada, descura da sua Universidade e não a inclui como, e nem exige que seja, a alavanca propulsora do progresso, um fator de libertação ou, como queria o meu saudoso Prof. Samuel Pessoa, uma comunidade de pesquisadores.

Assim, se quisermos chegar à raiz do problema, para bem compreendermos a nossa Universidade e a sua crise, temos de levar em conta a estrutura da nossa sociedade e a sua decorrente ideologia. A nossa sociedade é uma que, durante 322 anos, se desenvolveu como uma colônia de Portugal, a qual logo se viu estruturada para produzir bens para exportação através do trabalho escravo, o que beneficiava prima- 
riamente setores de fora do país e, concomitantemente, os senhores locais a eles associados. Esta estrutura básica adquiriu considerável complexidade através dos tempos, mas não desapareceu. Já nos primórdios da velha República, podíamos ver, segundo Basbaum, que "o modo de apropriação da terra, bem como o trabalho escravo e, a seguir, a miséria originada das relações sociais geradas pelo latifúndio, impediram a formação de um mercado interno. Assim, toda a produção se destinava ao exterior. Como conseqüência, essa produção baseada no mercado externo ficava sempre sujeita às oscilações deste mercado e à concorrência de outros países". Será que no fundamental mudamos muito? Hoje temos uma população de mais de 130 milhões de habitantes, temos áreas industrializadas bem modernas, mas temos também relações feudais e escravocratas no campo e o índio vivendo como na época do descobrimento (ou ainda em piores condições), temos megalópolis, gigantescas hidroelétricas e 25 milhões de menores abandonados; enfim, gritantes contrastes. A cada grau de transformação, crescimento e aumento da complexidade, a sociedade dominante brasileira soube habilmente se adaptar, com apenas pequenos abalos. Passamos pela independência política, a abolição da escravatura, períodos de ditadura militar, a velha e, agora, a Nova República e sempre contamos com o mito da índole pacífica do povo para fazermos os necessários ajustamentos e mantermos a mesma estrutura básica de desenvolvimento capitalista dependente. Este último não entra muito em choque com o modelo colonial de produzir bens para a exportação, para o benefício de uma pequena parcela da população, às custas do trabalho de uma imensa maioria de assalariados, os quais têm atrás de si uma legião de miseráveis desempregados que serve como reserva de mão-de-obra e, assim, ajuda a manter a exploração dos que conseguem trabalho. Os beneficiários não são mais o Rei de Portugal e sua côrte, mas os banqueiros internacionais que, apoiados nas forças das grandes potências capitalistas, nos parecem mais ávidos, mais ardilosos e muito mais fortes que nossos antigos colonizadores.

Mas, o importante para o meu presente objetivo não é constatar os indícios de estrutura colonial na nossa economia, mas sim a ideologia que dentro dela vem embutida. Já foi dito que nós não vivemos como pensamos, mas sim pensamos conforme vivemos. Se a nossa estrutura econômica mantém traços herdados do período colonial, a ideologia da nossa sociedade forçosamente reflete este fato. E é justamente a ideologia do colonialismo que impregna indelevelmente não só o pensamento dos que planejaram a nossa Universidade, mas também o de todos nós. Ainda há professores que acham que a Universidade é para ensinar, for- 
mar os doutores, mas não para pesquisar. Que os assuntos científicos não podem ser misturados com assuntos políticos. Que cultuam obsessivamente o saber dizer, mas que não se preocupam necessariamente com o saber fazer. Que estudante é para estudar e não pode imiscuir-se nos problemas da nação. Estes condicionamentos têm suas raízes nos tempos coloniais e persistem ao persistirem os traços coloniais da nossa economia. Daí podemos deduzir que toda sociedade gera a Universidade que merece, ou, em outras palavras, a que melhor serve aos seus interesses. "Parece perfeitamente claro - diz Werneck Sodré - que os pregadores da inferioridade brasileira quanto à possibilidade de explorarnıos as nossas riquezas com os nossos próprios recursos e e em próprio benefício, os que acreditam e proclamam que só poderemos nos desenvolver com a ajuda estrangeira, os que confiam apenas nos capitais externos para fomentar o nosso progresso, são herdeiros diretos daqueles que pregavam a superioridade racial, climática e geográfica dos países dominadores, e a nossa conseqüente inferioridade". "Os pessimistas de hoje que vêem o Brasil à beira do abismo, os que não acreditarn no povo, os que só confiam em elites, em predestinados, em bem-aventurados, os que nos supõem condenados à perdição econômica, os que se desalentam com os "desatinos" do nacionalismo, são herdeiros naturais dos que proclamavam a preguiça do brasileiro, a incapacidade do brasileiro, a cobiça do brasileiro". Devemos também lembrar que foi justamente quando se acentuaram as características da nossa dependência econômica, durante os 20 anos do regime militar, que a nossa Universidade conheceu a sua pior crise. Outras características da ideologia do colonialismo também aparecem refletidas na violência policial contra as massas populares, no desrespeito que consiste em privá-las de votar, nas mentiras que lhes são ditas e por vezes desmentidas com a maior sem-cerimônia, na insensibilidade com que se impõe um regime de recessão econômica a um país com 90 milhões de pobres famintos, para satisfazer in teresses externos.

Felizmente, agora abrem-se novas perspectivas, com a instalação de uma forma democrática de governo entre nós. $\hat{E}$ evidente que nada mudou substancialmente na estrutura econômica. Todavia, o fato novo desta vez é que o povo começa a ter participação no processo. As grandes massas nas praças públicas, clamando por eleições diretas e depois demonstrando maturação política ao jogar e ganhar com outras regras de jogo, representa acontecimento auspicioso. Com liberdade e participação de todos, poderemos conquistar novas vitórias. E a comunidade universitária, professores, estudantes e funcionários, deve saber que a Universidade está vinculada à sociedade a que serve. Portanto, ao lado 
do cumprimento dedicado, responsável e competente das atividades Universitárias, temos que nos interessar pelos problemas do país como um todo, preservando e ampliando a sua democracia, para o desenvolvimento de uma sociedade mais justa, mais progressista, mais livre e pacífica.

Zilton Andrade

Diretor do Centro de Pesquisas Gonçalo Moniz, Salvador - Fundação Oswaldo Cruz. 